\title{
Intellectual Capital Development: The Black Gold of Modern Organisation
}

\author{
Tamunomiebi, Dagogo Miebaka Kalio, Nissi \\ Department of Management, Faculty of Management Sciences, \\ Rivers State University, Port Harcourt, Nigeria
}

\begin{abstract}
Stretching and engaging the mind of the human resource within the organization for the sole aim of growth and profitability has birthed a high level of Intellectual capital development. The avoidance of organisational knowledge drain has also give the rise to philosophy supporting knowledge management structures in the organization and the value placement on intellectual capital development as an endowment has led to a growing interest in modern organisations as intellectual knowledge is built, shaped and blended to benefit the workforce. A basic understanding of the intellectual capital flow allows for leveraging of intellect as an asset. To this end, this paper considers intellectual capital development as a source of generated knowledge which is considered a black gold of modern organisation.
\end{abstract}

Keywords: Intellectual, Capital, Development, Black, Gold, Modern, Organisation

DOI: $10.7176 / \mathrm{EJBM} / 11-14-07$

Publication date:May $31^{\text {st }} 2019$

\section{Introduction}

The endowment of the mind with its ability to function in the capacity for higher forms of knowledge and thought patterns to positively affects an entire organisation pursuit for profitability and growth has given rise to look into intellectual capital development as a hidden goldmine for the organization: beyond the procurement of raw and untapped talent into the workplace, it has become needful that organisations translate her human resource into a very profitable economic voyage. Organisation must think of ways to stay afloat in the storms of turbulence, recession and fierce competition. Amazingly, Intellectual capital development is a rapidly growing topic that is of interest to organisations today and with an ever increasing economic improvement that ranges from knowledge gathering to information sharing down to innovation and creativity around shared knowledge (Itami, 1987, Coleman, 1988 and Burt, 1992). There is the demand to identify intellectuals and harness their strength and ability to any organisation, the value placement on employees in any work environment is one that provides skills, competence, technical know-how and expertise on the job and beyond. Employees are solution providers to issues within and outside the organization and as such their capacity need should be boosted by the organisation for solving workplace problems and tapping into the intellectual resources of these humans that work as employees. Organization's philosophy should support a structure that sustains individual talents and intellects to benefit all concerned by way of training and developing skill sets of humans. Intellectual capital development is also the combination of everything and everybody at the workplace that gives the organisation a favourable and competitive advantage over other organisations. A foresighted organisations that desires to remain relevant in these contemporary times must create a hub of knowledge and skills by way of having the right skill set in combination with the right knowledge. Intellectual capital development becomes relevant at the point where the organisation has a full grasp of the gold mine of individual knowledge. Knowledge or intellectual ability and property resides with the individual and the organisation really has no hold on any employee who want to be separated but the organisation must ensure that subjectivity of knowledge drain is averted through knowledge transfer by way of training and development. Intellectual capital development is a relatively new field and still undergoing different developmental stages. Intellectual capital development in today's modern organisations is worthwhile because emanated concepts and ideas are harnessed to keep the business relevant (Brown and Duguid, 2000). The workplace becomes a place for knowledge bank and such knowledge is shared to encourage learning and where learning is also translated into capital (Hackett, 2000).

\section{Intellectual capital}

Intellectual capital is a relatively new field of concern to organisations today who have understood the power of wealth creation through gathering knowledge, sharing knowledge and being innovative with the information at the disposal of the organisation. The base of intellectual capital development is hinged around the three foundations namely human capital, internal capital and external capital.

\section{The Foundations of Intellectual Capital development}

Intellectual capital development also entails recycling and management of knowledge via the formulation of strategic vision which ensures and aids the creation, update and shape of intellectual capital base. The combination 
of the three levels of the foundation of Intellectual capital development puts an organisation on the advantageous side on a scale with competitors. The truth is human capital, internal and external capital achieve one goal which is increasing the knowledge portfolio of the organisation. According to Edvinsson and Malone (1997), intellectual capital development is categorised as entailing three components which are:

\section{a) Human Capital}

The foundational skills, competences, experiences, value in addition to the trainings and educational qualifications of the individuals in the organisation is brought to bear at the organisation. Human members in the workplace collectively harness their knowledge, expertise, capabilities and know-how to the profitability of the organisation. Bontis (1998); Edvinsson (1997); and Sveiby (2000)) see human capital as the ability and proficiencies of an employee; in other words, an organization filled with highly educated and trained people or that invest in training its manpower stands to boost their chances of an increased human capital. According to Edvinsson (1997) buttressed that in an unrestricted economy, human capital or asset as it were is on hire in the organisation. Sveiby (2000) recaps that employees are agents in the business; all perceptible resources as well as the imperceptible relations are all products of human action and depend heavily on these employees for their continuity. Bontis (1998) would rather view the intellectual contributions or the human capital at the individual base. He went further to explain human capital as a blend of four factors namely:

1. genetic inheritance,

2. education,

3. experience, and

4. attitudes.

Bontis (1998) believed human capital is a source of innovation and premeditated regeneration from birthing and developing and idea through brainstorming, re-engineering, improvement of personal skills. He confessed that the core of human capital lies in the absolute intelligence and originality of the employee. Hines (2000) affirms this explanation of human capital by defining it as a combination of knowledge, skills, expertise, innovativeness and capability of the employees to deliver on the task in view of the organisation's values, culture and philosophy. Parnes (1984) and Zickner (1996) opined that the process involved in acquisition of knowledge is expensive either but highly motivated by a yearning for an improved productivity. Human capital is considered an investment to the overall organisation. Interestingly it was deduced by Hudson (1993) and Zickner (1996) that organisations with a high return on investment exceeded the rate at which human capital was developed through training of the workforce. Although Human capital is the property of the individual, resides in the individual, but organization can tap into it, rent and also replicate it through training. The use of technological tools is also key as it enables storage of knowledge for accurate and rapid delivery of such knowledge in the near future. Human capital value increases as employees are continuously educated and trained with the possibility of harnessing and guiding individual potentials by creating an atmosphere for learning, encourage the storage of knowledge which factors prospective employees and for the benefit of those who are not part of the initial learning process.

It impossible to talk about human capital without mentioning innovation; Innovation and creativity are imbedded in human capital. Innovation is a function intellect and motivation of the individual employees in the organization and can be considered a capital or a subset of human capital development since it is a rudimental feature. Inventions and innovations are also said to be the most specific and important and yet least predictable of the intellectual creations of man, but that they make progress and development possible. Sveiby (1998) and Edvinsson (1997) view innovation capital as an extract of human capital relating to the human intellect which brings about inventiveness and creativity: Innovativeness is initiated through human capital. According to Demarest (1997) in his twenty years of research affirmed that innovation at the workplace begins with the erection of new variety of knowledge and this knowledge should be used in some ways to avoid repeated mistakes of the past and it should be stored in captured information. It is not proven that Demarest was mistaken as he went further by saying one can deduce that there is innovation without assisted formal knowledge management systems. Hence, it is reasonable to question the necessity to formalize knowledge if there will be innovation.

Innovation is largely a collective process and continuous innovation within a period of time is required for any organisation to stay relevant. Smith (1998) admitted that increasing technological innovation is trimming down the gap between competitors. He reported that companies are considering the combined knowledge of the employees as a major competitive edge from which innovation can spring, and are rewarding and supporting, and encouraging the collaboration of people. Sveiby (1995) strongly advices that, although inventiveness and innovation can be major features in developing both strategies and technologies that makes future survival of an organisation possible.

\section{b) Internal Capital}

This can also be referred to as Organisational or Structural capital which processes information systems, databases, policies, intellectual property, culture. the enable database, processes and physical infrastructures of the organization that encourages human capital to function opttimally. Structural capital includes trademarks, processes and patents, as well as the proprietary software, database, information system and the organization's 
image. Due to its nature, structural capital can sub-grouped further into

a. The philosophy and system of the organisation for maximizing competence,

b. Techniques and procedures that are indulged for effective delivery goods and services.

c. Protection of intellectual property against copyright and trademark.

Structural capital is what remains after the employees are gone either by way of separation or transfer. Edvinsson (1997) considers structural capital as the outcome of all intellectual activities as recorded in the knowledge database, drawing, model, and documents. Structural capital implies the infrastructure that encourages knowledge to be recorded and shared. Structural capital at the organisational level makes it possible to build and measure intellectual capital and can be identified through the accumulation of knowledge owned by the organisation. Accumulated Knowledge is stored in systems forming a database. Bontis (1998) refers to structural capital as the structure and mechanism of the organisation that aid employees in their chase for effective performance and maximum business performance. He strongly advice that an individual can possess high intellectual capacity, and is encouraged to up activity with an exceptional quality, but if there is poor procedures and systems within the organisation it affects the action of the employees. He is of the notion that an organization having strong structural capital will have an assistive technology that permits individuals to try out ideas. The central point is that effort is saved and can be repeated by same or some other employee where the need arises especially when organized in information systems that encourages convert individual knowledge into group property. According to Lank (1997) believes that in order to guarantee proper and easy access to knowledge and information, the structural capital technology and system will need to provide room for information retrieval at three levels: which are explained below.

1. Reference purpose - this is a directory of specific and explicit information in electronic documents covering full text of lessons learnt, on reports, contract and proposals. This kind of knowledge ensures efforts are repeated and mistakes eliminated leaving employees to capitalize on their colleague's learning curves.

2. Expertise establishment - this is the assessment of implied knowledge via expertise list or databases, curriculum vitae (CVs) and competency profiles. This enable employees to sort the required expertise within the organisation when necessary and this most times is achieved via observation since it is often time implied.

3. Just-in-time feedback and networking - this is keeping in touch with global expertise and customers via video conferencing, telephone, chat facilities and e-mail. The idea here is to overcome geographical barrier and time wasters.

All three information retrieval levels are necessary because knowledge coding alone does not ensure efficient propagation nor does it necessarily result in more effective storage. The ability to have access to expertise is perhaps the one aspect that attention is required. Nonaka and Takeuchi (1995) maintains that knowledge displayed in numbers and words, only symbolizes very little of the whole but in addition knowledge should expressed in action that is visible. Emphases is laid on both explicit knowledge and tacit knowledge which aids understanding on shared opinions for effective organisational knowledge base to improve performance and profitability. It also creates a learning atmosphere that enables the workforce to learn from each other. Structural capital offers a very robust connection that supports the advancement of the external capital.

\section{c. External Capital}

This is a relationship or customer-based capital covering all external knowledge spanning from suppliers, partners, clients with a focal on brand names, trademarks and reputation. Intellectual capital development all the time cuts across the employee and organisation to the affiliates of the organisation by way of buying or selling to the organisation and this relationship is foster on knowledge and this knowledge is two-way. This is an era where the customer's choices are effortlessly defined; all that is required relationship for organisations to get to know their customers. Duffy (2000) holds the notion that an established worth of one's external capital is necessary to consider the value of the knowledge entrenched in the customers, suppliers, partners etc. These are all intangibles that are outside the formal structure of the firm. According to Bontis $(1998, p$ 67) the knowledge of customer relationships is the major source of external capital. He further explained that organisations must recognize that they can access the wealth of knowledge of their client by way of research and development on products and services, through surveys or word of mouth. We must understand that the customer is an individual that is well endowed with skills and expertise and most time have an external view of the organisation's activity. Duffy believes that this capital does not come easily and he considers it external tto the organisation's core and say it most difficult to develop (Duffy, 2000). According to Bontis (1998) he added that external capital value is a function of time. The client's worth is key and as such organisations must understand that a customer's stay-put value is of more importance to the organisation than acquiring a new customer. He further explained that is it less expensive to tend to an existing customer than a new one because consideration is highly needful as regards the knowledge of employees tending to the needs of these customer. Sveiby (2000) buttressed that organisattions that are knowledge focused pay attention to their clients for the level of knowledge contributed via interaction and this kind relationship is as asset 
or customer capital, it helps generate and maintain information about the clients and the business, the products, competitors etc.

The information gathered from suppliers, partners and the community where the organisation is situated gives an organisation direction. The core asset of any orgnisation is knowledge gathered, managed and retrieved when and where necessary. External capital is generated from society, culture and technologically

\section{Developmental Stages of Intellectual Capital Development}

Intellectual capital is broadly recognised as one of the most momentous resources of modern organisations (a black gold indeed) and it has sailed through different stages. In developing intellectual capital, the question as to where does one start is key. Dearlove (2000) identified four models in the development of intellectual capital and this model is in phases.

Figure 1. The four model phases of Intellectual capital development

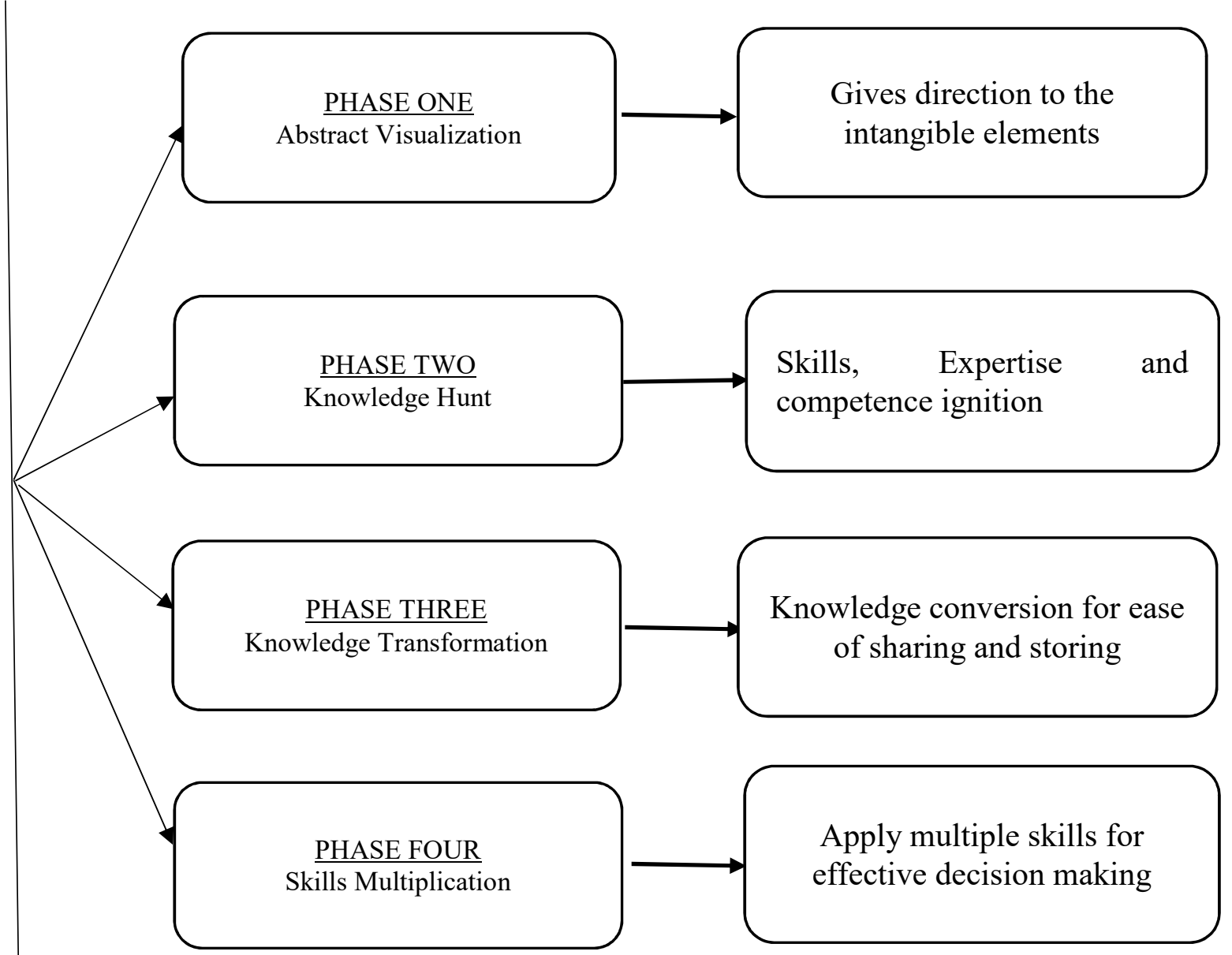

Source: Researcher's desk 2018

The model phases of Intellectual Capital Development

1. Phase 1 - The visualization of abstract gives direction to the concept of intellectual capital from an imaginative perspective to reality.

2. Phase 2 - The search for skills, expertise, competencies, value is ignited based on the visualized abstract. 3. Phase 3 - Generated skill set is processed and methodologically transformed into systemic or structural capital with the aim of sharing knowledge as a multiplier of human skills and expertise.

4. Phase 4 - The focus on multiplying skills is to apply such expertise to solving needs and problems at the organisation's front.

According to Bontis (1998), Edvinsson (1997), Roos and Roos (1997), Stewart (1994) and Zickner (1996), established that the vision and commitment of management at the apex is not sufficient enough to guarantee the success of intellectual capital development. The organisation must understand the need to discover that the bottom line is not the only deciding factor for organisation's success and as such strategic steps should be followed managing skills and helping the organization thrive. The development phases intellectual capital does not necessarily follow a pattern as illustrated above, it is flexible enough to overlap (Edvinsson, 1997).

Developing Intellectual Capital 
According to Russ (2015), Intellectual capital is a support system on thought leadership campaigns. Decisions on intellectual capital are wider, infact they are broad-based e.g. projected and actual audience in contrast to referral points and to lay emphasis on the thought leadership initiative. He mentioned two focus principles namely: i. Solution focused - Intellectual capital as a principle deals with recommendations and referrals, it is customer/employee focused for classified information and outcomes

ii. regarding the what to, when to, why to and where to of the organisation.

iii. $\quad$ Perspective focused. Intellectual capital here deals with expected or existing conditions which includes the trends, forecast and insights for organisations in making significant and viable explanations.

He believed that the decision on which course to track on potentials areas can be transformed into intellectual capitals; Intellectual capital development is more converting and enhancing raw knowledge and to achieve this, approaches such as concept generation technique and market research are implored. Concept generation techniques is the recognition, identification and authentication of new idea and skillfully reforming interestingly old and new target spectators. Brainstorming is generally accepted in the concept generation techniques. Individuals obey all set rules and procedures considering factors and forces to transform potentials into intellectual capital. The development of quantitative and qualitative research in identifying and refining intellectual capital which is more a Market research functions in the following capacity:

i. $\quad$ Validation

ii. Quantification

iii. Distillation

iv. Interpretation.

Market research uncovers and improves the functionality of intellectual capital by producing new applicability and approaches on intellectual capital with a foundation on a research-based though.

\section{Preserving Intellectual Capital}

The challenge we face today as organisations spans from workforce separation: retrenchment, death, resignation, retirement, transfer and relocation. It is also disheartening to know that when employee are separated from the organisation, they leave with acquired knowledge. The organization is not individual-bound and as such does not have a hold on the individual who willing wants to move but succession plan with respect to knowledge gathering on the job or on a task is needful for efficiently and effectively running the organisation.

Amazingly, employees are so knowledgeable on the job and discover new skill by working on assigned task (knowing what work best). This discovered knowledge can be captured and made available to others through the aid of technology e.g, videos, and audios, pod cast, online seminars, broadcast etc. The storage of extant knowledge is improved and preserved by technology. Knowledge is a vital resource to organization, whether tacit or explicit knowledeg. The success or failure of the workplace is a function of the knowledge that is developed and management at the individual or group level.

Deborah (2009) emphasized on the importance of identifying, recognizing and sustaining intellectual capital. Employers must look for way to access to employee's knowledge through training, recording of such training and saving it on a device or on the cloud for future training on the job. Intellectual capital in as much as it is and asset can also be a challenge. Organisation ways to preserve their talent where necessary or sustain knowledge as the case maybe. Beyond the generated knowledge at organization, the industry also benefits from the information.

\section{Conclusion}

There is a positive mind shift when information and knowledge generated from the employees, customers and the overall structure of the organisation is considered important; everyone will want to give more. Organisational structures should be learning driven so as to play around information and not leaving it in the hands of few individual because the exit of such individuals ends everything about that knowledge. Human capital development in relation to staff training, internal capital development in relation to value and rand, external capital development in relation to client's perception and taste etc. Mind shift of such enables both the staff members and the employer to recognize that a connection exists between the organisation and each person. This relationship lies on a collective responsibility to values, goals and ideas and to managerial processes. The values as long as the employee remains in the organisation for human capital, challenge as earlier pointed out still remains that the employee is not a property that is owned and there is the tendency to move on, ut the structure should have measures in place to transfer expertise, skills and the application of know-how. Intellectual capital development will be a lack gold indeed when the modern orgnisattion's survival is not a factor of a talented and skillful employee: a mechanism has to be ground for knowledge generation and transfer before the employee (s) leave the organisation. Goodwill of customers, clients and suppliers should be considered highly too.

\section{Reference}

Allen, T. (1970), Roles in technical communication networks. In: C. E. Nelson, D. K. Pollack (Eds), 
Communication Among Scientists and Scientists and Engineers. Lexington MA: Heath Lexington Books, D.C. Heath and Company, pp. 191-208.

Allen, T. (1 977), Managing the Flow of Technology: Technology Transfer and the Dissemination of Technological Information Within the R\&D Organization. The Massachusetts Institute of Technology.

Argyris, C., Schon, D. (1978), Organizational Learning: A Theory of Action Approach. Reading: Addison Wesley.

Blacker, F. (1995), Knowledge, knowledge work and organization: An overview and interpretation, Organization Studies, 16 (6), 1021-1048.

Burden, P. (2000), Knowledge Management: The Bibliography, Medford, Information Today.

Brooking, Annie (1997). Intellectual capital. International. Thomson Business Press.

Culnan, M. (1987), Mapping the intellectual structure of MIS, 1980-1985, MIS Quarterly, 11 (3), 341-353.

Culnan, M. (1986), The intellectual development of management information systems 1972-1982: A co-citation analysis, Management Science, 32 (2), 156-172.

Cohen, W. (1990), Absorptive capacity: A new perspective on learning and innovation, Administrative Science Quarterly, 35, 128-152.

Davenport, T., Prusak, L. (1998), Working Knowledge; How Organizations Manage What They Know, Boston, Harvard Business School Press.

Stead, D. (2009), Are your employees just bidding their time. Business Week Article Nov. 16, 2009.

Drucker, P. (1993), The Post-Capitalist Society, New York, Harper.

Edvinsson L, Malone M S (1997), Intellectual Capital: Realizing Your Company's True Value by Finding its Hidden Brainpower, HarperBusiness Press, New York, NY.

Elizabeth, Lank (1998) 'Building Structural Capital: A New Key to Generating business Value' Wiley Online Library, 3(4), 56-61

Choo, Chun Wei, and Nick Bontis (2002), The strategic management of intellectual capital and organizational knowledge. Oxford University Press.

Coleman, J.S. (1988). 'Social Capital in the Creation of Human Capital', The American Journal of Sociology, 9(4), 95-120

Gary Smith (1998) 'Learning Statistics by Doing Statistics', Journal of Statistics Education, 6(3), 22 - 29

Grant, R. (1991), The resource-based theory of competitive advantage: Implication for strategy formulation, California Management Review, 33 (3), 114-135.

Grant, R. (1996), Towards a knowledge-based theory of the firm, Strategic Management Journal, 17 (Winter special issue): 109-122.

Hair, J., Anderson, R., Tatham, R., Black, W. (1998), Multivariate Data Analysis, Upper Saddle River, Simon \& Schuster.

Hamel, G., Prahalad, C. (1994), Competing for the Future, Boston, Harvard Business Schools Press.

Hedlund, G., Nonaka, I. (1993), Models of knowledge management in the West and Japan, Implementing Strategic Processes: Change, Learning, and Co-operation. Lorange, Chakravarthy, Roos, Van De Ven (Eds).

Karl-Erik Sveiby (2001) 'A knowledge-based theory of the firm to guide in strategy formulation', Journal of intellectual capital, 2(4), 344-358

Khavand Kar, Jalil \& Khavandkar, Ehsan. (2013), "Intellectual Capital: Management, Development and Measurement Models" (3rd edition), Ministry of Science, Research and Technology Press.

Luthy, David, H (1998) "Intellectual capital and its measurement." Proceedings of the Asian. Pacific Interdisciplinary Research in Accounting Conference (APIRA), Osaka, Japan.

Ravi, Arora. (2002) 'Implementing KM- a balance score card approach', Journal of knowledge Management, 6(3), $240-249$.

Russ, Alan Prince (2015), How to develop intellectual capital, Forbes Magazine (www.forbes.com/sites/russalanprince/2015/06/07/how-to-devellop-imtellectual-capital/amp/

Stewart, Thomas, A (1997), Intellectual Capital: The New Wealth of Organizations, Doubleday. New York, NY.

Ståhle, P., Ståhle, S. and Lin, C.Y.Y. (2015) 'Intangibles and national economic wealth - a new perspective on how they are linked', Journal of Intellectual Capital, 16(1), 20-57. doi: 10.1108/jic-02-2014-0017.

Wiig, Karl M (1997). "Integrating intellectual capital and knowledge management." Long range planning 30(3), $399-405$ 